TITLE:

\title{
High HOMO levels and narrow energy band gaps of dithienogalloles
}

$\operatorname{AUTHOR}(S)$ :

Matsumoto, Takuya; Tanaka, Kazuo; Chujo, Yoshiki

CITATION:

Matsumoto, Takuya ...[et al]. High HOMO levels and narrow energy band gaps of dithienogalloles. RSC Advances 2015, 5(68): 55406-55410

ISSUE DATE:

2015-06-24

URL:

http://hdl.handle.net/2433/201947

RIGHT:

This journal is (C) The Royal Society of Chemistry 2015.; The full-text file will be made open to the public on 19 June 2016 in accordance with publisher's 'Terms and Conditions for Self-Archiving'.; この論文は出版社版でありません。引用の際 には出版社版をご確認ご利用ください。; This is not the published version. Please cite only the published version. 


\section{High HOMO Levels and Narrow Energy Band Gaps of Dithienogalloles}

Takuya Matsumoto ${ }^{a}$, Kazuo Tanaka ${ }^{* b}$ and Yoshiki Chujo ${ }^{* b}$

${ }^{a}$ Department of Chemical Science and Engineering, Graduate School of Engineering, Kobe University, Rokko, Nada-ku, Kobe, 657-85011, Japan

${ }^{b}$ Department of Polymer Chemistry, Graduate School of Engineering, Kyoto University,

Katsura, Nishikyo-ku, Kyoto 615-8510, Japan

*(Y.C.) E-mail: chujo@chujo.synchem.kyoto-u.ac.jp.

*(K.T.) E-mail: kazuo123@chujo.synchem.kyoto-u.ac.jp.

Key Word

Dithienogallole, Gallole, Fused thiophene, Heterole, Thiophene 


\begin{abstract}
We synthesized dithieno[3,2-b:2'3'-d] galloles containing four-coordinated gallium atoms. It was found that dithienogalloles had high stability to air and moisture and showed narrower energyband gaps than dithienosiloles which are commodity materials in organic opto and/or electronic devices. In addition, relatively-higher HOMO levels were observed from dithienogalloles than those of other dithienoheteroles from electrochemical measurements. We experimentally and theoretically demonstrated the electron-donating properties and resonance effects of gallium atoms of dithienogalloles.
\end{abstract}


Aromatic-ring-fused thiophenes are versatile building blocks because of a wide applicability for modern organic-based electronic devices. ${ }^{1}$ In particular, dithienoheterole and their derivatives have received much attention. Various kinds of heteroatoms such as nitrogen, ${ }^{2}$ phosphorus, ${ }^{3}$ bismuth, ${ }^{4}$ sulfur, ${ }^{2 a, b, 5}$ silicon, ${ }^{2 a, 6}$ germanium ${ }^{7}$ and $\operatorname{tin}^{8}$ have been incorporated into the dithienoheterole structure, and their optical and electrochemical properties were prominently studied. It was revealed that some of these compounds had high potential as basic structures for photovoltaic cells, ${ }^{2,5 a, 6,7}$ light-emitting diodes ${ }^{1,6 c}$ and field-effect transistors. ${ }^{1 \mathrm{a}-\mathrm{c}, 2,5,6}$ Furthermore, unique electronic states originated from boron atoms such as anti-aromaticity and high reductive potentials were clarified from dithienoboroles. ${ }^{9}$ Thereby, the introduction of group 13 elements into the dithienoheterole structures is a topic with high relevance. Indeed, the optical and electrochemical properties of heteroles of heavier group 13 elements have been presented in the most recent reports. ${ }^{10}$ However, the high sensitivities of heteroles with heavier group 13 elements have made the investigation of their material properties challenging. Hence, to prove the uniqueness and to explore the further functional materials, the synthesis of new series of dithienoheteroles with heavier group 13 elements and understanding their characteristics are of great significance.

We have recently reported the facile synthesis and the unique optical properties of gallafluorenes. The emission via the excited triplet states and the weak electronic interaction between the aromatic units through four-coordinated gallium atoms, namely broadly-defined conjugation, were presented. ${ }^{11}$ To establish chemistry in conjugated materials involving group 13 elements, further examples to offer the electronic effect of gallium atoms on $\pi$-conjugation systems are essential. From this stand point, herein, we demonstrate the synthesis and characterization of dithieno[3,2$\left.b: 2^{\prime} 3^{\prime}-d\right]$ galloles. We evaluated the electronic and resonance effects of four-coordinated gallium 
atoms based on the comparison with other dithienoheteroles (Figure 1) to gather the information on fundamental electronic properties of gallium-containing conjugated molecules.

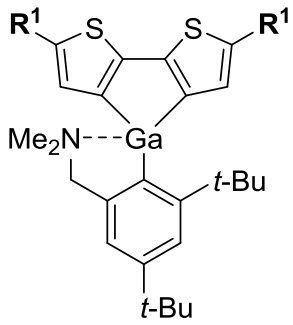

GaDT $\left(\mathbf{R}^{1}=\mathrm{H}\right)$ GaDT-TMS $\left(\mathbf{R}^{1}=\right.$ TMS $)$

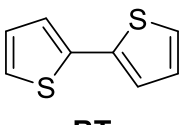

BT

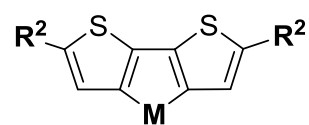

$\operatorname{SiDT}\left(\mathbf{R}^{2}=\mathrm{H}, \mathbf{M}=\mathrm{SiMe}_{2}\right)$ SiDT-TMS $\left(\mathbf{R}^{\mathbf{2}}=\mathrm{TMS}, \mathbf{M}=\mathrm{SiMe}_{2}\right)$

CDT $\left(\mathbf{R}^{2}=\mathrm{H}, \mathbf{M}=\mathrm{CMe}_{2}\right)$

NDT $\left(\mathbf{R}^{2}=\mathrm{H}, \mathbf{M}=\mathrm{NC}_{8} \mathrm{H}_{17}\right)$

NDT' $\left(\mathbf{R}^{2}=\mathrm{H}, \mathbf{M}=\mathrm{NMe}\right)$

Figure 1. Chemical structures of dithienogalloles and other dithienohetelole derivatives.

We designed dithienogalloles where gallium atoms were protected by Mamx groups (Mamx = 2,4-di-tert-butyl-6-[(dimethylamino)methyl]phenyl). ${ }^{12}$ According to Scheme 1, we synthesized dithienogalloles (GaDT and GaDT-TMS) through the reaction with dilithiobithiophenes and Mamx $\mathrm{GaCl}_{2}$. GaDT and GaDT-TMS showed stability to air and moisture and were able to be stored for at least one month under ambient atmosphere.
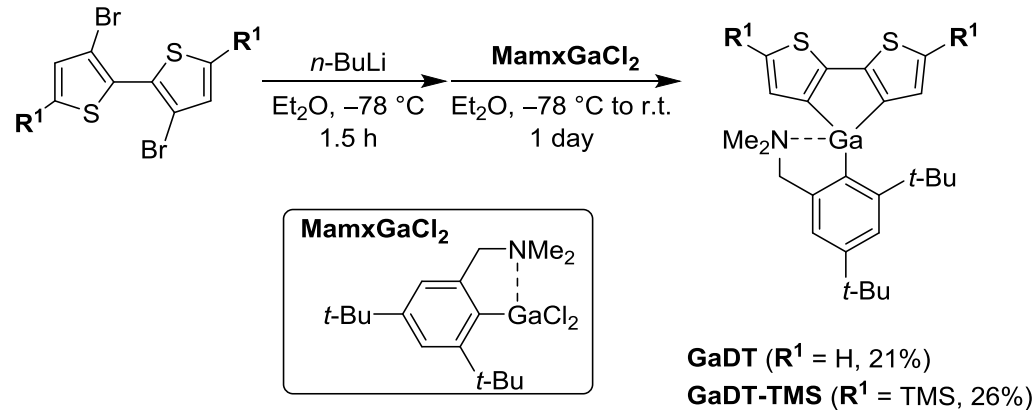

Scheme 1. Synthesis of dithienogalloles GaDT and GaDT-TMS. 
(a)

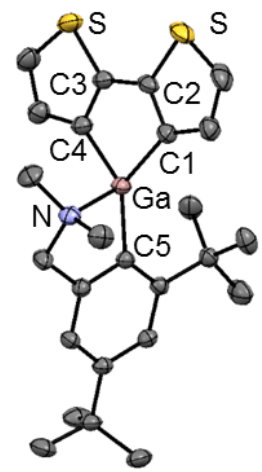

(b)

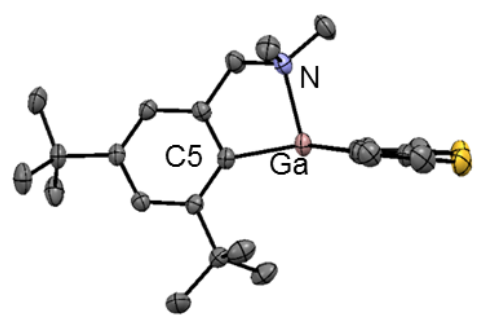

Figure 2. ORTEP drawings of (a) GaDT and (b) side view (30\% probability for thermal ellipsoids). Hydrogen atoms are omitted for clarity. Selected bond lengths $(\AA)$ and angles $\left({ }^{\circ}\right)$ : Ga-N 2.092(3), $\mathrm{Ga}-\mathrm{C} 1$ 1.983(3), Ga-C4 2.004(3), Ga-C5 1.971(3), C1-Ga-C4 89.95(12), C1-Ga-C5 138.92(11), C4-Ga-C5 125.63(11), C1-Ga-N 104.57(11), C4-Ga-N 105.69(11), C5-Ga-N 86.38(10), C1C2-C3-C4 3.6(4).

The geometry of GaDT was determined by an X-ray diffraction analysis of single crystal as described in Figure 2. The length of Ga-N bond was $2.091 \AA$ and comparable to well-known coordinated bond lengths of nitrogen to gallium atoms [reported $\mathrm{Ga}-\mathrm{N}$ bond lengths: 2.013-2.178 $\left.\AA^{11,12 \mathrm{~b}, 13}\right]$. The sum of $\mathrm{C}-\mathrm{Ga}-\mathrm{C}$ angles was $354.49^{\circ}$ and similar to those of other organogallium compounds with Mamx groups [sums of $\mathrm{C}-\mathrm{Ga}-\mathrm{C}$ angles of the reported organogallium compounds: $\left.352.7-358.6^{\circ 11,12 b}\right]$. The sum of $\mathrm{C}-\mathrm{Ga}-\mathrm{N}$ angles was $296.7^{\circ}$ and comparable to those of reported organogallium compounds with Mamx groups [sums of $\mathrm{C}-\mathrm{Ga}-\mathrm{N}$ angles of the reported organogallium compounds: $294.9-297.3^{\circ 11,12 b}$. The structure around the gallium atom was similar to the trigonal planar structure coordinated by nitrogen from upper side. The dihedral angle of $\mathrm{C}(1)-\mathrm{C}(2)-\mathrm{C}(3)-\mathrm{C}(4)\left(3.7^{\circ}\right)$ was small and the moiety of bithiophene had a planar structure.

We investigated the optical properties of GaDT and GaDT-TMS and compared to those of bithiophene (BTH), cyclopenta-dithiophene (CDT) and dithienosiloles (SiDT and SiDT-TMS). In Figure 3, their UV-vis absorption and photoluminescence spectra are represented. Optical data are listed in Table 1. The absorption band of CDT appeared at $316 \mathrm{~nm}$, and the red-shift of the 
peak position was observed compared to that of BDT. It is likely that higher planarity of the bithiophene unit induces these changes. The red-shifted absorption band of GaDT was observed at $342 \mathrm{~nm}$ relative to not only that of CDT but also SiDT (338 nm). These data mean that GaDT has a narrower energy band gap than CDT and SiDT. The $\sigma^{*}-\pi^{*}$ conjugation of their silole moieties in SiDT is responsible for the narrower energy band gap. Similarly, GaDT-TMS showed the narrower energy band gap than SiDT-TMS. The decrease of energy band gap of dithienosiloles compared to CDT are caused by $\sigma^{*}-\pi^{*}$ conjugation of their silole moieties. ${ }^{6}$ These facts suggest that the decrease of the band gaps of dithienogalloles should be attributed to the fixedconformation of the bithiophene units as well as the electronic effect of the four-coordinated gallium atoms.
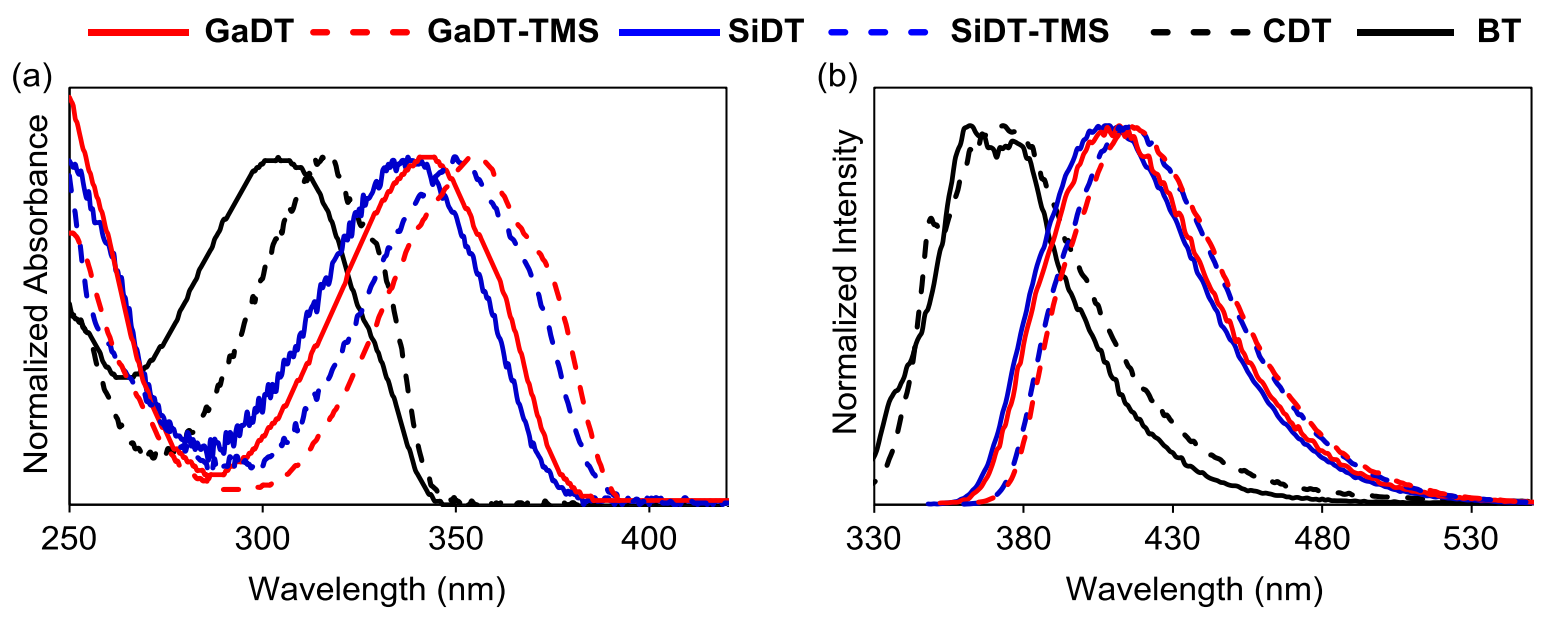

Figure 3. (a) UV-vis absorption and (b) photoluminescence (excited at $\lambda_{\text {max,abs}}$ ) spectra of $1.0 \times$ $10^{-5}$ M GaDT (solid red), GaDT-TMS (dashed red), SiDT (solid blue), SiDT-TMS (dashed blue), CDT (dashed black) and BT (solid black) in THF. 
Table 1. UV-vis absorption and photoluminescence data for dithienoheteroles ${ }^{a}$

\begin{tabular}{|c|c|c|c|c|c|}
\hline & $\begin{array}{l}\lambda_{\max , \mathrm{abs}} \\
(\mathrm{nm})^{b}\end{array}$ & $\begin{array}{l}\lambda_{\text {onset,abs }} \\
(\mathrm{nm})^{c}\end{array}$ & $\begin{array}{l}\lambda_{\max , \mathrm{FL}} \\
(\mathrm{nm})^{d}\end{array}$ & $\Phi_{\mathrm{F}}^{e}$ & $\tau_{1 / 2}(\mathrm{~ns})^{f}$ \\
\hline GaDT & 342 & 377 & 412 & 0.52 & $\begin{array}{l}5.63(100 \%) \\
\left(\chi^{2}=1.09\right)\end{array}$ \\
\hline GaDT-TMS & 355 & 390 & 416 & 0.89 & $\begin{array}{l}3.74(100 \%) \\
\left(\chi^{2}=1.04\right)\end{array}$ \\
\hline SiDT & 338 & 374 & 408 & 0.54 & $\begin{array}{l}5.20(100 \%) \\
\left(\chi^{2}=0.98\right)\end{array}$ \\
\hline SiDT-TMS & 350 & 385 & 416 & 0.76 & $\begin{array}{l}3.82(100 \%) \\
\left(\chi^{2}=0.81\right)\end{array}$ \\
\hline CDT & 316 & 344 & 373 & 0.05 & $<0.05$ \\
\hline BT & 304 & 343 & 362 & 0.13 & $<0.05$ \\
\hline
\end{tabular}

${ }^{a}$ Optical measurements were performed for $1.0 \times 10^{-5} \mathrm{M}$ in THF solution. ${ }^{b}$ Absorption maxima. ${ }^{c}$ Onset wavelength of absorption bands. ${ }^{d}$ Fluorescence maxima excited at $\lambda_{\text {max,abs. }}{ }^{e}$ Absolute

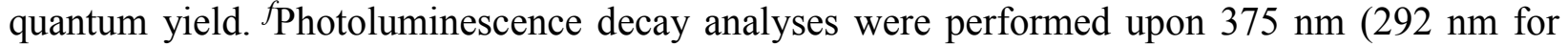
CDT and BT) excitation by a UV diode laser.

In photoluminescence spectra, the emission bands of GaDT and GaDT-TMS also appeared in the red-shifted wavelength regions at $412 \mathrm{~nm}$ and $416 \mathrm{~nm}$ compared to CDT (373 $\mathrm{nm}$ ). Their wavelengths were similar to those of SiDT (408 nm) and SiDT-TMS (416 nm), respectively. The absorption and emission bands of dithienogalloles were slightly effected by solvents (Figures S11 and S12 in the Supporting Information). These facts suggest that the emission bands of GaDT and GaDT-TMS are mainly attributed to $\pi-\pi^{*}$ transitions. In addition, the red-shifts of emission bands should be caused by the electronic effect of the gallium atoms, as described in the previous section of the absorption spactra. The short emission lifetimes in nanosecond orders represent that these emissions were fluorescence. Moreover, GaDT and GaDT-TMS showed high quantum yields similarly to SiDT and SiDT-TMS. Particularly, the quantum yield of GaDT-TMS was 0.89. This tendency was observed in the case of dithienostannoles. ${ }^{8 a}$ New emission bands of GaDT and GaDT-TMS hardly appeared at 77K (Figure S13 in the Supporting Information). This result 
means that intersystem crossing hardly proceeded in the synthesized dithienogalloles. Thereby, high quantum yields could be obtained. These data propose that dithienogallole units are promising to be used as fluorescence emitting materials.

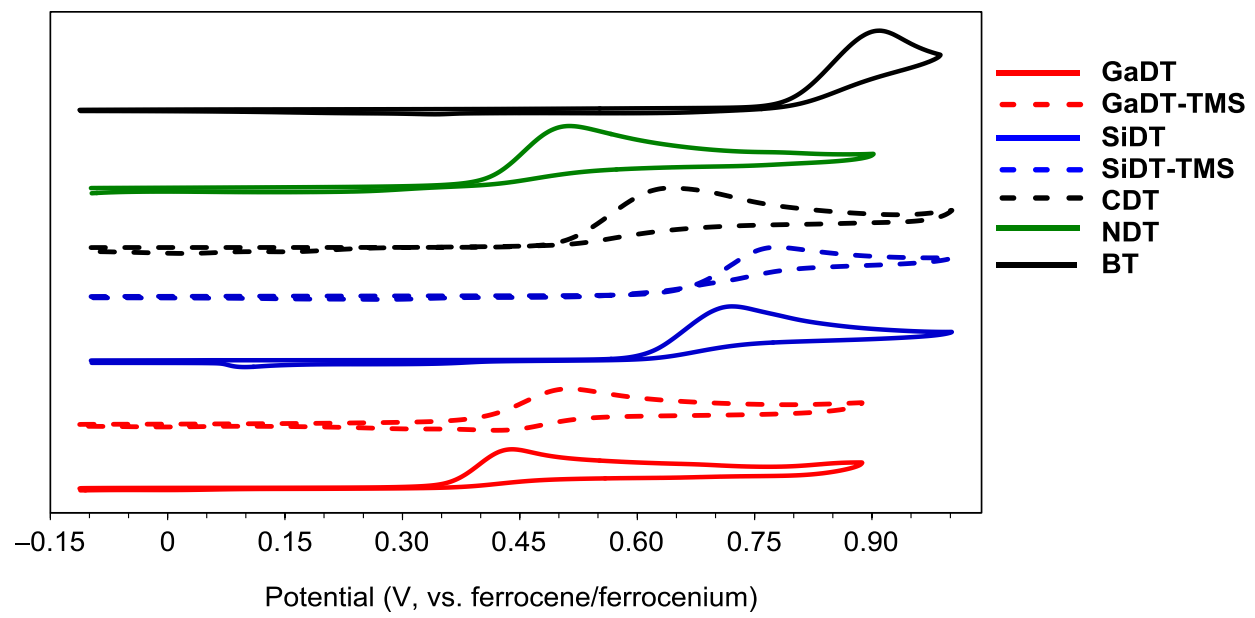

Figure 4. Cyclic valtammograms of $1.0 \mathrm{mM}$ GaDT (solid red), GaDT-TMS (dashed red), SiDT (solid blue), SiDT-TMS (dashed blue), CDT (dashed black) NDT (solid green) and BT (solid black) in $\mathrm{CH}_{3} \mathrm{CN} / \mathrm{CH}_{2} \mathrm{Cl}_{2}(6: 1)$ solution containing $\mathrm{NBu}_{4} \mathrm{PF}_{6}(0.10 \mathrm{M})$ using a Pt working electrode, a $\mathrm{Pt}$ wire counter electrode, an $\mathrm{Ag} / \mathrm{AgCl}$ reference electrode, and a ferrocene/ferrocenium external standard at room temperature with a scan rate of $0.05 \mathrm{Vs}^{-1}$.

Table 2. Results of CV measurements, energy levels of frontier orbitals for dithienoheteroles. ${ }^{a}$

\begin{tabular}{lccccc}
\hline & $\begin{array}{c}E_{\mathrm{g}}{ }^{b} \\
(\mathrm{eV})\end{array}$ & $\begin{array}{c}E_{\mathrm{cp}}{ }^{\text {ox } c} \\
(\mathrm{~V})\end{array}$ & $\begin{array}{c}E_{\mathrm{onset}^{0 \mathrm{ox}} d} \\
(\mathrm{~V})\end{array}$ & $\begin{array}{c}E_{\mathrm{HOMO}}{ }^{e} \\
(\mathrm{eV})\end{array}$ & $\begin{array}{c}E_{\mathrm{LUMO}}{ }^{f} \\
(\mathrm{eV})\end{array}$ \\
\hline GaDT & 3.29 & 0.44 & 0.36 & -5.16 & -1.87 \\
GaDT-TMS & 3.18 & 0.51 & 0.40 & -5.20 & -2.02 \\
SiDT & 3.32 & 0.72 & 0.61 & -5.41 & -2.09 \\
SiDT-TMS & 3.22 & 0.78 & 0.66 & -5.46 & -2.24 \\
CDT & 3.60 & 0.64 & 0.50 & -5.30 & -1.70 \\
NDT & 3.91 & 0.51 & 0.41 & -5.21 & -1.30 \\
BT & 3.62 & 0.91 & 0.80 & -5.60 & -1.98 \\
\hline
\end{tabular}

${ }^{a} \mathrm{CV}$ measurements were carried out in $\mathrm{CH}_{3} \mathrm{CN} / \mathrm{CH}_{2} \mathrm{Cl}_{2}$ (6:1) solution containing $\mathrm{NBu}_{4} \mathrm{PF}_{6}(0.10$ $\mathrm{M})$ using a Pt working electrode, a Pt wire counter electrode, an $\mathrm{Ag} / \mathrm{AgCl}$ reference electrode, and a ferrocene/ferrocenium external standard at room temperature with a scan rate of $0.05 \mathrm{Vs}^{-1}$. ${ }^{b} E_{\mathrm{g}}$ were estimated from the onset wavelength of absorption spectra of dithienoheteroles. ${ }^{c}$ Oxidation potential at the peak top of oxidation wave of dithienoheteroles. ${ }^{d}$ Oxidation potential at the onset of oxidation wave of dithienoheteroles. ${ }^{e} E_{\mathrm{HOMO}}=-\left(4.8+E_{\mathrm{onset}}{ }^{\mathrm{ox}}\right) .{ }^{f} E_{\mathrm{LUMO}}=E_{\mathrm{HOMO}}+E_{\mathrm{g}}$. 
In Figure 4 and Table 2, we describe the results of cyclic voltammograms (CV) and the energy levels of frontier molecular orbitals of dithienoheteroles estimated from the measurement results. In all the dithienoheteroles, the oxidation waves and their peaks were observed. GaDT showed the onset of oxidation wave at $0.36 \mathrm{~V}$ and lower oxidation potential than CDT $(0.50 \mathrm{~V})$ and dithienopyrrole (NDT, $0.41 \mathrm{~V}$ ), which have electron-donating carbon or nitrogen atoms at the bridgehead of cyclopentadithiophenes. These data indicate that the highest occupied molecular orbital (HOMO) level of GaDT was higher than other dithienoheteroles. The oxidation potential of GaDT-TMS was elevated by the trimethylsilyl groups compared to GaDT. Nevertheless, the value of the onset of the oxidation wave of GaDT-TMS was $0.40 \mathrm{~V}$ and similar level with that of NDT. These facts indicate that the four-coordinated gallium atoms would show strong electrondonating properties toward the bithiophene units. We estimated the energy band gaps $E_{\mathrm{g}}$ of dithienoheteroles from the onsets of the UV-vis absorption bands, the energy levels of HOMOs based on $E_{\text {HOMO }}=-\left(4.8+E_{\text {onset }^{\mathrm{ox}}}\right),{ }^{14}$ and the energy levels of lowest unoccupied MO (LUMO) based on $E_{\mathrm{LUMO}}=E_{\mathrm{HOMO}}+E_{\mathrm{g}}$. The HOMO levels of GaDT $(-5.16 \mathrm{eV})$ and GaDT-TMS $(-5.20$ $\mathrm{eV})$ were higher than or comparable to that of NDT $(-5.20 \mathrm{eV})$. In contrast, the LUMO levels of GaDT $(-1.87 \mathrm{eV})$ and GaDT-TMS $(-2.02 \mathrm{eV})$ were almost similar to those of BT $(-1.98 \mathrm{eV})$ and CDT $(-1.70 \mathrm{eV})$, and lower than that of NDT $(-1.30 \mathrm{eV})$. These results suggest that the electron-donating characteristics of the gallium atoms critically affect the energy levels of HOMOs. The electron-donating properties of the gallium atoms less significantly influence to LUMOs. 


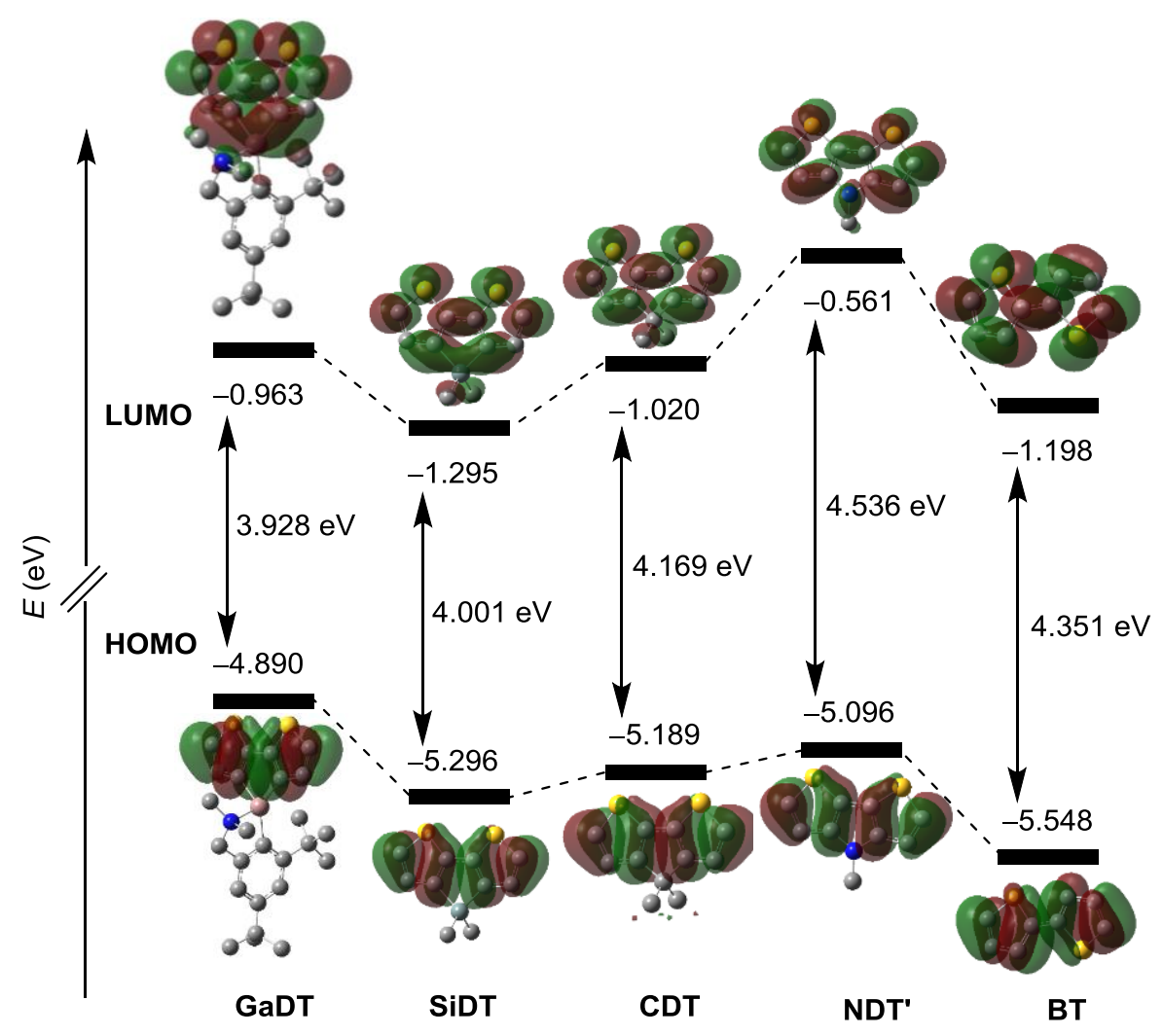

Figure 5. Energy diagram and frontier orbitals of GaDT, SiDT, CDT, NDT' ${ }^{\prime}$ and BT calculated by the DFT method (B3LYP/6-31G(d,p)//B3LYP/6-311+G(2df) levels for gallium atoms and B3LYP/6-31G(d,p) levels for others. Hydrogen atoms are omitted for clarity.

For the further comprehension of the electronic interaction between the gallium atoms and the bithiophene units, we carried out density functional theory (DFT) and time-dependent DFT (TDDFT) calculations. All the geometries of dithienoheteroles were optimized at the B3LYP/6$31 \mathrm{G}(\mathrm{d}, \mathrm{p})$ levels, and the transitions and energy states were calculated at the B3LYP/6-311+G(2df) levels for gallium atoms and the B3LYP/6-31G(d,p) levels for others using the optimized geometries. The calculated frontier molecular orbitals and energy diagrams of dithienoheteroles in the $\mathrm{S}_{0}$ ground states are illustrated in Figure 5 and Figure S14 in the Supporting Information. The results of the optimization of their structures and the contributions of energy transitions are described in Tables S5-S18 in the Supporting Information. Accordingly, the HOMO of GaDT is 
localized only on the bithiophene units, while the LUMO is distributed on the bithiophene unit and gallium atom. The allowed transition at $334 \mathrm{~nm}$ for GaDT is mainly attributed to the excitations from HOMO to LUMO as observed in other dithienoheteroles. In addition, the HOMO-LUMO band gap of GaDT is $-3.928 \mathrm{eV}$ and narrower than that of SiDT $(-4.001 \mathrm{eV})$. The energy level of HOMO of GaDT is $-4.890 \mathrm{eV}$ and higher than those in other dithienoheteroles. On the other hand, the energy level of LUMO of GaDT is $-0.963 \mathrm{eV}$ and similar to that of CDT $(-1.020 \mathrm{eV})$ and lower than that of NDT' $(-0.561 \mathrm{eV})$. These calculation results show good qualitative agreements with the energy levels of the frontier orbitals and HOMO-LUMO band gaps obtained from optical and electrochemical measurements. The localization of HOMO only on the bithiophene unit suggests that the increase of HOMO level should be caused by the electron-donating property of the four-coordinated gallium atom. The LUMO level of GaDT should be lowered and stabilized by the delocalization of molecular orbital involving gallium atom compared to that of NDT'. This stabilization of the LUMO level was elucidated in our previous work. ${ }^{11 \mathrm{~b}}$ In other words, the increase of HOMO levels results from the inductive effect of the four-coordinated gallium atom. Furthermore, the stabilization of LUMO level is attributed to the resonance effect of the gallium atom. Therefore, the narrower HOMO-LUMO band gap of GaDT is accomplished.

In conclusion, we synthesized air- and moisture-stable dithieno[3,2-b:2'3'- $d$ ] galloles not only for the creation of functional materials but also for the fundamental investigation on electronic effects of the four-coordinated gallium atoms. From single crystal X-ray structure analysis, the gallium atom of the synthesized dithienogallole had a four-coordinated structure, and the geometry of the gallium atom was similar to the trigonal planar structure coordinated by nitrogen from upper side. The optical and electrochemical measurements and theoretical calculation results revealed the increasing of HOMO levels by the electronic-donating effects of the four-coordinated gallium 
atoms and the stabilization of LUMO levels by the gallium-containing conjugation. Consequently, the narrower HOMO-LUMO band gaps of dithienogalloles than those of dithienosiloles were observed. In addition, the high quantum yield of GaDT-TMS was obtained. Dithienogalloles and their derivatives could be promising compounds for organic electronic devices. 


\section{Notes}

The authors declare no competing financial interest. 


\section{ACKNOWLEDGEMENTS}

This work was partially supported by "the Adaptable and Seamless Technology Transfer Program" through target-driven R\&D, Japan Science and Technology Agency (JST) and a Grant-in-Aid for Scientific Research on Innovative Areas "New Polymeric Materials Based on Element-Blocks (No.2401)" (24102013) of The Ministry of Education, Culture, Sports, Science, and Technology, Japan.

\section{NOTES AND REFERENCES}

1. (a) M. Mas-Torrent and C. Rovira, Chem. Rev. 2011, 111, 4833-4856; (b) J. Mei, Y. Diao, A. L. Appleton, L. Fang and Z. Bao, J. Am. Chem. Soc. 2013, 135, 6724-6746; (c) K. Takimiya, S. Shinamura, I. Osaka and E. Miyazaki, Adv. Mater. 2011, 23, 4347-4370; (d) Y. Kim and E. Lim, Polymers 2014, 6, 382-407; (e) T. Baumgartner, J. Inorg. Organomet. Polym. 2005, 15, 389-409.

2. (a) S. Zhang, Y. Guo, H. Fan, Y. Liu, H.-Y. Chen, G. Yang, X. Zhan, Y. Liu, Y. Li and Y. Yang, J. Polym. Sci. A Polym. Chem. 2009, 47, 5498-5508; (b) X. Zhan, Z. Tan, E. Zhou, Y. Li, R. Misra, A. Grant, B. Domercq, X.-H. Zhang, Z. An, X. Zhang, S. Barlow, B. Kippelen and S. R. Marder, J. Mater. Chem. 2009, 19, 5794-5803; (c) T. L. Nelson, T. M. Young, J. Liu, S. P. Mishra, J. A. Belot, C. L. Balliet, A. E. Javier, T. Kowalewski and R. D. McCullough, Adv. Mater. 2010, 22, 4617-4621; (d) W. Vanormelingen, K. Van den Bergh, T. Verbiest and G. Koeckelberghs, Macromolecules 2008, 41, 5582-5589.

3. (a) T. Baumgartner, T. Neumann and B. Wirges, Angew. Chem. Int. Ed. 2004, 43, 6197-6201;

(b) Y. Dienes, S. Durben, T. Kárpáti, T. Neumann, U. Englert, L. Nyulászi and T. Baumgartner, 
Chem.-Eur. J. 2007, 13, 7487-7500; (c) C. Romero-Nieto, S. Merino, J. Rodríguez-López and T. Baumgartner, Chem.-Eur. J. 2009, 15, 4135-4145.

4. J. Ohshita, S. Matsui, R. Yamamoto, T. Mizumo, Y. Ooyama, Y. Harima, T. Murafuji, K. Tao, Y. Kuramochi, T. Kaikoh and H. Higashimura, Organometallics 2010, 29, 3239-3241.

5. (a) X. Zhan, Z. '. Tan, B. Domercq, Z. An, X. Zhang, S. Barlow, Y. Li, D. Zhu, B. Kippelen and S. R. Marder, J. Am. Chem. Soc. 2007, 129, 7246-7247; (b) F. Cicoira, C. Santato, M. Melucci, L. Favaretto, M. Gazzano, M. Muccini and G. Barbarella, Adv. Mater. 2006, 18, $169-174$.

6. (a) J. Ohshita, Macromol. Chem. Phys. 2009, 210, 1360-1370; (b) L. Liao, L. Dai, A. Smith, M. Durstock, J. Lu, J. Ding and Y. Tao, Macromolecules 2007, 40, 9406-9412; (c) J. Ohshita, K. Kimura, K.-H. Lee, A. Kunai, Y.-W. Kwak, E.-C. Son and Y. Kunugi, J. Polym. Sci. A Polym. Chem. 2007, 45, 4588-4596.

7. (a) C. P. Yau, Z. Fei, R. S. Ashraf, M. Shahid, S. E. Watkins, P. Pattanasattayavong, T. D. Anthopoulos, V. G. Gregoriou, C. L. Chochos and M. Heeney, Adv. Funct. Mater. 2014, 24, 678-687; (b) C. E. Small, S. Chen, J. Subbiah, C. M. Amb, S.-W. Tsang, T.-H. Lai, J. R. Reynolds and F. So, Nat Photon 2012, 6, 115-120; (c) D. Gendron, P.-O. Morin, P. Berrouard, N. Allard, B. R. Aïch, C. N. Garon, Y. Tao and M. Leclerc, Macromolecules 2011, 44, 71887193; (d) J. Ohshita, M. Miyazaki, D. Tanaka, Y. Morihara, Y. Fujita and Y. Kunugi, Polym. Chem. 2013, 4, 3116-3122.

8. (a) D. Tanaka, J. Ohshita, Y. Ooyama, N. Kobayashi, H. Higashimura, T. Nakanishi and Y. Hasegawa, Organometallics 2013, 32, 4136-4141; (b) M. Saito, M. Shiratake, T. Tajima, J. D. Guo and S. Nagase, J. Organomet. Chem. 2009, 694, 4056-4061. 
9. (a) A. Iida and S. Yamaguchi, J. Am. Chem. Soc. 2011, 133, 6952-6955; (b) S. Kim, K.-H. Song, S. O. Kang and J. Ko, Chem. Commun. 2004, 68-69.

10. (a) T. Agou, T. Wasano, P. Jin, S. Nagase and N. Tokitoh, Angew. Chem. Int. Ed. 2013, 52, 10031-10034; (b) T. Agou, T. Wasano, T. Sasamori and N. Tokitoh, Organometallics 2014, 33, 6963-6966; (c) T. Agou, T. Wasano, T. Sasamori and N. Tokitoh, J. Phys. Org. Chem. 2015, 2, 104-107; (d) M. Saito, T. Akiba, M. Kaneko, T. Kawamura, M. Abe, M. Hada and M. Minoura, Chem. Eur. J. 2013, 19, 16946-16953.

11. (a) T. Matsumoto, K. Tanaka and Y. Chujo, J. Am. Chem. Soc. 2013, 135, 4211-4214; (b) T. Matsumoto, Y. Onishi, K. Tanaka, H. Fueno, K. Tanaka and Y. Chujo, Chem. Commun. 2014, 50, 15740-15743; (c) T. Matsumoto, K. Tanaka and Y. Chujo, Macromolecules, 2015, 48, 1343-1351; (d) T. Matsumoto, H. Takamine, K. Tanaka and Y. Chujo, Org. Lett., 2015, 17, 1593-1596. (e) T. Matsumoto, K. Tanaka, K. Tanaka and Y. Chujo, Dalton Trans., 2015, DOI: 10.1039/C5DT00718F.

12. (a) B. Bagh, J. B. Gilroy, A. Staubitz and J. Müller, J. Am. Chem. Soc. 2010, 132, 1794-1795;

(b) B. Bagh, G. Schatte, J. C. Green and J. Müller, J. Am. Chem. Soc. 2012, 134, 7924-7936;

(c) M. Yoshifuji, K. Kamijo and K. Toyota, Tetrahedron Lett. 1994, 35, 3971-3974.

13. (a) B. Bagh, N. C. Breit, K. Harms, G. Schatte, I. J. Burgess, H. Braunschweig and J. Müller, Inorg. Chem. 2012, 51, 11155-11167; (b) B. Bagh, N. C. Breit, J. B. Gilroy, G. Schatte and J. Müller, Chem. Commun. 2012, 48, 7823-7825; (c) P. Jutzi, H. Sielemann, B. Neumann and H.-G. Stammler, Inorg. Chim. Acta 2005, 358, 4208-4216; (d) J. A. Schachner, G. A. Orlowski, J. W. Quail, H.-B. Kraatz and J. Müller, Inorg. Chem. 2005, 45, 454-459; (e) B. Quillian, Y. Wang, P. Wei, C. S. Wannere, P. R. Schleyer and G. H. Robinson, J. Am. Chem. 
Soc. 2007, 129, 13380-13381; (f) H. Schumann, U. Hartmann, W. Wassermann, A. Dietrich, F. H. Görlitz, L. Pohl and M. Hostalek, Chem. Ber. 1990, 123, 2093-2099.

14. (a) J. Pommerehne, H. Vestweber, W. Guss, R. F. Mahrt, H. Bässler, M. Porsch and J. Daub, Adv. Mater. 1995, 7, 551-554; (b) C. M. Cardona, W. Li, A. E. Kaifer, D. Stockdale and G. C. Bazan, Adv. Mater. 2011, 23, 2367-2371. 


\section{TOC}



